\title{
Exploring Expressive Sandwork as a Form of Psychosocial Care: A Case
}

\section{Study of a Vulnerable Adolescent}

\author{
BRIEF REPORT
}

\author{
Carien Lubbe-De Beer \& Imme Thom
}

University of Pretoria

\author{
*Address correspondence to: \\ Carien Lubbe-De Beer, PhD, Department of Educational Psychology, Faculty of Education, University of \\ Pretoria, Groenkloof campus, Aldoel Room 2-29, Republic of South Africa, 0002 \\ E-mail: carien.lubbe@up.ac.za
}

\section{Abstract}

This paper explores the use of expressive sandwork as a form of psychological support for a youth with psychosocial vulnerability. A case study, which emanated from a community outreach project, is briefly described of a male black participant, from a low socioeconomic background, who is currently in correctional services care. The participant engaged with sandplay over five weekly sessions, lasting approximately an hour each. The data obtained during these sessions were thematically analyzed and the findings suggest that expressive sandwork enabled this individual to become more aware of his emotional wellbeing and foster a sense of hope. This brief report suggests that expressive sandwork offers a form of short-term psychological support in circumstances where limited or no help is available.

Key words: Expressive sandwork, sandplay, psychotherapy, Jungian sandplay, vulnerable communities 
Expressive sandwork is sandplay therapy that has the aim of maximizing psychosocial care. This form of therapy is useful in resource-scarce areas and vulnerable communities.

Sandtray therapy can be used as a diagnostic projective tool, and/or as therapy. Various theoretical viewpoints can be applied to sandtray work, for example Gestalt theory. In sandplay, or Kalffian sandplay as it is sometimes referred to (Bradway, 2006), a Jungian analytical perspective is applied. Interpretation follows the Jungian tradition including taking note of the process of individuation as described by Jung (Bradway, 2006). Individuation refers to the process of becoming conscious of human wholeness. In this context, wholeness refers to an attitude that strives for the integration of opposites within oneself (Kalff, 1980).

Aims and procedures of sandplay. The aim of sandplay is to activate healing energies at the deepest level of the psyche through the use of miniatures and the sand in order to reflect the client's inner world. Through this symbolic activity and the experience of free and creative play, unconscious processes are made visible in three-dimensional form. A basic premise of sandplay therapy is that the psyche possesses a natural tendency to heal itself, given the proper conditions (Ammann, 1991; Bradway \& McCoard, 1997; Kalff, 1980; Mitchell \& Friedman, 1994). In a sandtray the individual creates a world that relates to his/her personal and social reality (Dale \& Lyddon, 2000). A basic premise of sandplay is that it allows for or creates a free and protected space for the client's imagination to emerge (Mitchell \& Friedman, 1994). The protected space lies in the therapist's recognition of the client's boundaries, where negative or destructive tendencies are not suppressed but transformed, and the free space is a space of acceptance, care, empathy and respect in order to create a secure setting. With sandplay the therapist largely stays out of the process and lets self-healing subsequently take place, guided by the client's psyche.

Expressive sandwork takes place in groups, but each individual is able to undergo their own individual sandwork process. The clients each work with an adult, who observes 
and documents their sandwork (Pattis Zoja, 2011). These adults are accompanying volunteers who are neither psychotherapists nor psychologists, but students, social workers or, most often, trained volunteer community workers.

The volunteer's role is to act as an individual observer for a specific individual (client/participant), observing and documenting the psychosocial processes relating to body language, mood and other nonverbal indicators. The psychologist or therapist, meanwhile, interacts freely with the clients, engaging in facilitative conversations with both the clients and the volunteers.

For this case study, we followed a hermeneutic single case efficacy design (McLeod 2010) with the primary aim of exploring the effectiveness and applicability of expressive sandwork in vulnerable communities. Our specific research question was "How can insight into the applicability of expressive sandwork in vulnerable communities inform sandplay theory and multicultural counseling?"

\section{Method}

\section{Case description}

Kumalo (pseudonym), who is 18 years of age, is an only child who was raised by his mother. He grew up in a disadvantaged community characterized by poverty and crime. At the age of 17 he and members of a gang were arrested for murder, and detained at a correctional services facility. When the sandplay intervention took place he had been in prison for about 18 months, and was still awaiting trial.

\section{Data collection and procedure}

The data were collected by utilizing the case/progress notes, photographs of the completed sand trays, observations such as body language, mood or other nonverbal 
indicators captured in the therapy notes, as well as small informal discussions with relevant role players (e.g. the guards at the prison facility).

The group format for this type of therapy can materialize in various ways. In this project we made use of a self-designed wagon which accommodates up to twelve sandtrays. Each volunteer stands next to or slightly behind each client/participant whilst they are busy with their sandplay process.

The basic requirements for sandplay were met, namely, trays measuring $28^{1 / 2} \times 19^{1 / 2} \times$ 3 inches, painted blue and filled with sand. Participants were invited to create a scene in the sand, and they were given some explanation relating to the sand, the blue bottom of each tray, the figurines and the fact that water could be added if they wanted to. As little as possible is actually said, however; usually just an invitation such as, "Would you like to do a sandplay?" After the participants have completed the sandtray the observer asks: "Tell me more about your story" and the story is then captured. Then, in a group format, volunteers ask questions relating to the story for clarification, depending on volunteers' experience and skill level. Photographs are also taken of each completed sandplay picture. The confirmability of data observations was achieved by the two authors who worked collaboratively on the interpretations (Rule \& John, 2011).

Permission for the study was granted by a local NGO called Shongolollo SGfB, with whom the second author was involved with, as well as the prison authorities. These authorities included the local prison board and the relevant district office. The participants were inmates of the prison who had volunteered and had consented in writing to take part. The second author conducted the sandplay sessions during times allocated by the local prison board. The project spanned approximately two years, but each participant was only seen for four to five sessions. The participant in this reported case study completed five sessions. The intervention data were analyzed by both authors after the intervention. 


\section{Data analysis}

The data were analyzed by means of inductive thematic data analysis (Nieuwenhuis, 2007). In the interpretation process, two alternative approaches were followed; namely, one that supports the effective outcome of the intervention (the affirmative stance), and one that supports a conclusion that the intervention was not effective (the critical stance). Plausibility criteria (McLeod, 2010) were used to determine changes in the client and to determine whether they could be related to the intervention or not.

\section{Descriptions}

Various expressive sandplay scenarios resulted: (i) inner resource exploration, (ii) connecting with the past and happier times, (iii) enhanced self-regulation, (iv) emergence of a deep inner crisis and (v) fostering hope. Each of these is considered next.

\section{Sandwork 1: Exploration of inner resources available for possible solutions}

The first sand tray is depicted in Figure 1. In the foreground Kumalo appears to situate his African personhood in a display in which community members are cleaning inside a circle in which he figuratively sits. This might indicate a collective or "community of selves" that constitutes his internal world (Mkhize, 2004). Furthermore, it would seem that this young adult is on an inward journey to find the self and that he might be undergoing a cleansing process. Note the two figures at the back of the tray, which he explains as someone being taken prisoner. Furthermore, note the shells on the right. The symbolic meaning of shells in traditional sandplay is usually associated with femininity, birth and good luck, whereas the right-hand side can indicate anything to do with the future (Bradway, 2001). 


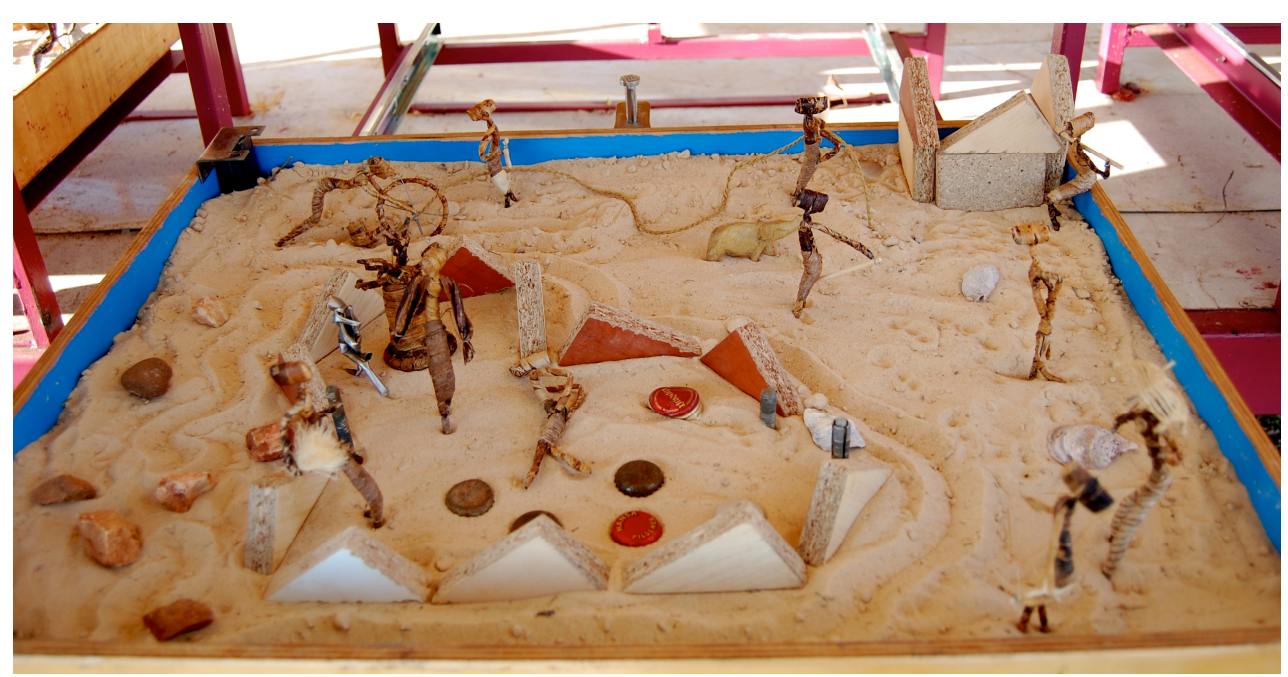

Figure 1: Kumalo's first tray depicting an exploration of inner resources.

\section{Sandwork 2: Connecting with the past and happier times}

In the second sandtray, Kumalo again builds a circle, and perceives himself as being listened to by animals in a zoo. The animals that are listening to him could be representative of his emotions and inner drives, which he is slowly starting to contain. He also depicts himself as standing expectantly close to a gate that leads out. This could be indicative of a focus on a new beginning; or perhaps a solution to conflict (Bradway, 2001).

\section{Sandwork 3: Enhanced emotional self-regulation}

His third display depicted in figure 2 includes four hills, which might be either a quest for order or an order found within the chaos that surrounds his life. Four could also indicate the limitations of his present situation (Bradway, 2001). There is an outward movement of animals, which he says are tame and able to leave. This continuation from tray two seems to support the suggestion made relating to his ability to regulate his emotions and his inner world. This seems to be confirmed by the observation of his body language in terms of which Kumalo appeared calm and happy. 


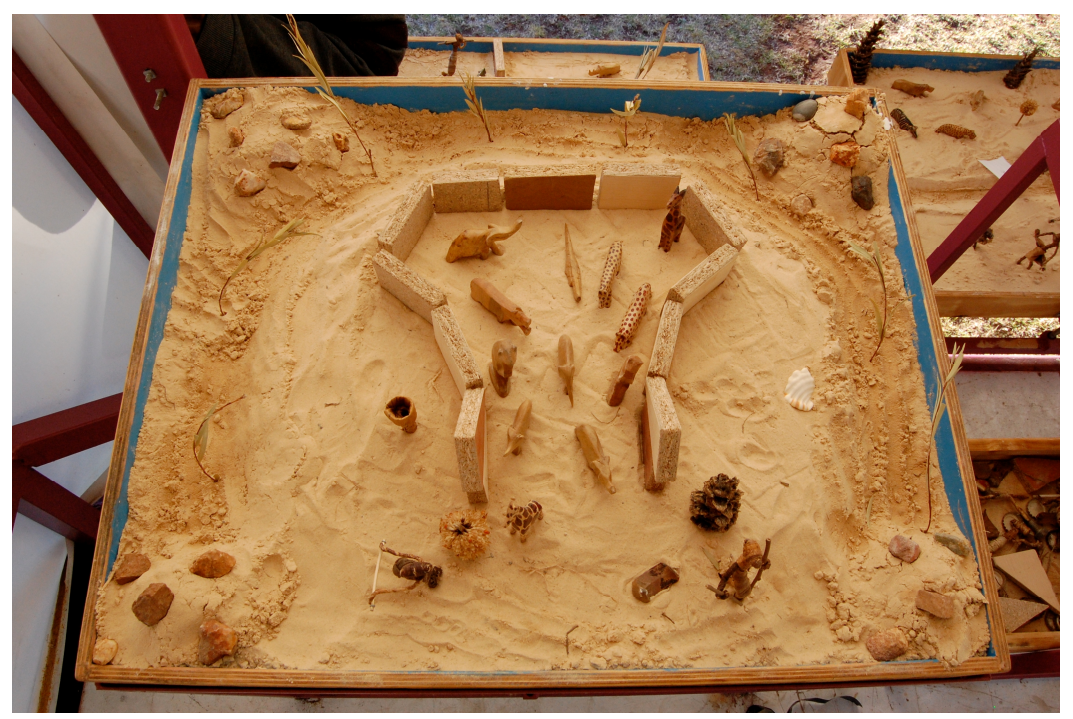

Figure 2: Kumalo's third tray

\section{Sandwork 4: Emergence of deep inner crisis}

At the time Kumalo was in a very depressed state. Accordingly, he built a barren scene with the tray quite empty. This gives the impression of being lost and hopeless, and with having no escape from his circumstances. He built what he says is the Day of Judgment. He said: "What is the difference; one way or the other I am eternally condemned." In response the psychologist provided supportive therapy by sharing with Kumalo the fact that there are many belief systems in the world that have forgiveness as a core theme.

\section{Sandwork 5: Fostering hope}

Kumalo divided the sand into two parts and placed a shell in a rectangle on the right. On the left he placed people in his display who he said "will never be free, because they cannot remove the obstacles in their way. They do not believe that the shell can absorb guilt and sin". He says he has now broken free from the imprisonment on the left-hand side.

A positive outlook emerges, as well as sense of hope which is evident in his words "you are allowed to start anew". From a Kalffian sandplay perspective, this can be seen as the 
beginning of a union of opposites, which is essential in the analytical process as described earlier (Kalff, 1980).

\section{Discussion}

By engaging with the sand and in telling his story, the beginning of hope was fostered. Wright (2012) argues that properties such as being forsaken, judged and abandoned, as seen in tray 4, work against the emergence and nurturance of hope (as seen in tray 5). From a positive psychological framework, the fostering of hope can serve as a protective factor that shields the individual against harsh circumstances. According to Snyder, Rand and Sigmon (2005), hope serves to drive emotions and people's wellbeing.

Expressive sandwork appears to hold the possibility for enabling the therapist to enter the world of the client (Smaby \& Maddux, 2011). In this case study the therapist was able to offer an accepting and non-judgmental space and to create an atmosphere of love, support, care and unconditional regard. These qualities are mainly non-verbal in nature, but the fact that the young adult confronted his past, connected with painful memories and faced the harsh reality of his current situation is perhaps indicative that the therapist was able to create a free and protective space.

The case study shows the inner resources available to the participant to face and uncover hidden memories and trauma, and the first tentative steps that were taken towards healing and integration. As Taki-Reece (2010) observes, sandwork offers individuals an opportunity to talk about their everyday lives, their concerns and their deep inner feelings, even if this happens after the sandplay process has been completed.

The limitations of the study include the highly speculative interpretations of the sandtray displays. More evidence is thus needed on the reproducibility of interpretations with participants who display vulnerability. 


\section{References}

Ammann, R. (1991). Healing and transformation in sandplay, creative processes become visible. La Salle, IL: Open Court Publishing.

Bradway, K. (2006). What is sandplay? Journal of Sandplay Therapy, 15(2), 7-9.

Bradway, K., \& McCoard, B. (1997). Sandplay, silent workshop of the psyche. London/New York: Routledge.

Dale, M. A., \& Lyddon, W. J. (2000). Sandplay: A constructivist strategy for assessment and change. Journal of Constructivist Psychology, 13, 135-154.

Kagee, A., \& Lundt, C. (2012). Psychology training directors' reflections on evidence-based practice in South Africa. South African Journal of Psychology, 42(1), 103-113.

Kalff, D. (1980). Sandplay, a psychotherapeutic approach to the psyche. Santa Monica, CA: Sigo.

McLeod, J. (2011). Case study research in counseling and psychology. London: SAGE.

Mitchell, R. R., \& Friedman, H. S. (1994). Sandplay: Past, present, and future. New York: Routledge.

Mkhize, N. (2004). Sociocultural approaches to psychology:Dialogism and African conceptions of the self. . In D. Hook,N. Mkhize, P. Kiguwa, A. Collins, E. Burman, \& I. Parker (Eds.), Critical psychology (pp. 53-83). Lansdowne, South Africa: UCT Press.

Nieuwenhuis, J. (2007). Analysing qualitative data. In K. Maree (Ed.), First steps in research (pp. 99-117). Pretoria: Van Schaik.

Pattis Zoja, E. (2011). Sandplay therapy in vulnerable communities: A Jungian approach. New York: Routledge.

Rule, P., \& John, V. (2011). Your guide to case study research. Pretoria: Van Schaik. 
Seedat, M., \& Lazarus, S. (2011). Community psychology: Origins, developments, and manifestations. Journal of Community Psychology, 39(3), 241-257.

Smaby, M. H., \& Maddux, C. D. (2011). Basic and advanced counselling skills. California, USA: Brooks/Cole, Cengage Learning.

Snyder, C. R., Rand, K. L., \& Sigmon, D. R. (2005). Hope theory: A member of the positive psychology family. In C. R. Snyder, \& S. J. Lopez. (Eds.), Handbook of positive psychology. New York: Oxford University Press.

Taki-Reece, S. (2010). Ah, Hakoniwa! Sand, pebbles and bottle caps, shone brightly under the southern cross. Journal of Sandplay Therapy, 19(2), 21-32.

Wright, C. (2012). Conversations about doing hope: A narrative therapeutic journey exploring hope with young people from the child-headed household. Unpublished doctoral thesis. Johannesburg: University of Johannesburg. 